\title{
Skill and strategic control
}

\author{
Ellen Fridland ${ }^{1}[0$
}

Received: 26 May 2020 / Accepted: 21 January 2021 / Published online: 8 February 2021

(c) The Author(s) 2021

\begin{abstract}
This paper provides an account of the strategic control involved in skilled action. When I discuss strategic control, I have in mind the practical goals, plans, and strategies that skilled agents use in order to specify, structure, and organize their skilled actions, which they have learned through practice. The idea is that skilled agents are better than novices not only at implementing the intentions that they have but also at forming the right intentions. More specifically, skilled agents are able formulate and modify, adjust and adapt their practical intentions in ways that are appropriate, effective, and flexible given their overall goals. Further, to specify the kind of action plans that are involved in strategic control, I'll rely on empirical evidence concerning mental practice and mental imagery from sports psychology as well as evidence highlighting the systematic differences in the cognitive representations of skills between experts and non-experts. I'll claim that, together, this evidence suggests that the intentions that structure skilled actions are practical and not theoretical, that is, that they are perceptual and motor and not abstract, amodal, or linguistic. Importantly, despite their grounded nature, these plans are still personal-level, deliberate, rational states. That is, the practical intentions used to specify and structure skilled actions are best conceived of as higher-order, motor-modal structures, which can be manipulated and used by the agent for the purpose of reasoning, deliberation, decision-making and, of course, the actual online structuring and organizing of action.
\end{abstract}

Keywords Skill · Intention · Practical intention · Motor schema $\cdot$ Action schema · Strategic control

\section{Skill and the strategic level of control}

While much of skilled action happens "under the radar" it's important to acknowledge that a significant part of skill also involves good old-fashioned thinking. This point has been persuasively defended by intellectualists, especially Jason Stanley

Ellen Fridland

Ellen.fridland@kcl.ac.uk; ellenfridland@gmail.com

1 King's College London, Strand, London WC2R 2LS, UK 
when he highlights in a paper with Stanley and Krakauer (2013), the impossibility of performing a skill without having knowledge of what to do in order to perform it. For instance, there is no way to be a skilled tennis player, if you don't know that you have to, e.g., pick up the racket and swing it towards a ball. ${ }^{1}$ Even though this kind of knowledge is far from sufficient for skill, since it can be shared by both skilled and unskilled tennis players, this fact doesn't undermine the necessity of such knowledge for paradigmatic cases skilled action. In fact, knowledge of what one needs to do seems to be required for intentional action in general and since skills, when instantiated, are a kind of intentional action (Ryle 1949; Stanley and Willlamson 2001; Noë 2005; Bengson and Moffett 2011; Stanley and Krakauer 2013; Fridland 2014; Pavese 2018), it is no surprise that this kind of knowledge has a role to play in skilled action as well.

The strategic aspects of skill, however, are not limited to having knowledge about what needs to be done in order to perform a skill. They can also include, for instance, the kind of decisions we make about how to approach the performance of a skill. We may, for instance decide to perform aggressively, defensively, or energetically (Papineau 2013). Or we may decide that it is worth holding back and taking it easy during practice, rehearsal, the early stages of a performance, or the preliminary games in a tournament. In aesthetic or expressive skills, we may decide on the feeling or mood that we'd like the performance to evoke. For instance, that we want the piano piece to sound angry or a dance to feel mournful. In difficult or unusual circumstances, we may need to think about how to tackle a familiar task (Christensen et al. 2016). We may also think and plan the sequence or series of actions that we will perform in order to instantiate the skill, for instance, planning the moves in a gymnastics routine or the stages of a cooking process. These kinds of choices have significant impacts on the performance of skilled action and we'd be missing something important, if we didn't acknowledge how much reflective thinking is involved in skill. Of course, these strategic aspects of skill can be learned through practice but they don't necessarily have to be learned in this way. One may, for example, learn about when it is best to play defensively in soccer without learning to actually play in that way. One may learn about an effective regimen of practice without practicing at all. That is, there's a lot about this aspect of skill that can be shared by both skilled agents and novices or even fans and observers.

Crucially, however, as I'll argue below, there are also goals, plans and strategies that guide skill, which can only be developed as a result of practice. This means that practice is required not only for automatizing certain motor components of skilled action but for refining and structuring the practical intentions that specify and organize the instantiations of those skilled actions. As such, skilled agents uniquely possess strategic, practical, organizing intentions that structure their skilled actions in appropriate and effective ways. In this way, part of being skilled is knowing and

\footnotetext{
1 This conception of knowledge as necessary for skill focuses on ordinary cases of skill and does not address the thorny issues of Gettierized know how. For more on this problem, see, for instance: Poston (2009) and Cath (2011).
} 
planning, in a practical manner, what one is going to do. And it is not enough to know about the skill, to have these kinds of organizing intentions.

When I discuss strategic control, then, I have in mind the practical goals, plans, and strategies that skilled agents use in order to specify, structure, and organize their skilled actions, which they have learned through practice. The idea is that skilled agents are better than novices not only at implementing the intentions that they have but also at forming the right intentions. ${ }^{2}$ More specifically, skilled agents are able formulate and modify, adjust and adapt their practical intentions in ways that are appropriate, effective, and flexible given their overall goals. Note that control, as I have previously defined it (removed for review) refers to the ability, acquired through practice, to adapt, adjust, modify, and correct appropriately, effectively, and flexibly given one's goals and the situation. Taking this into account, what I'm claiming here is that skilled agents have strategic control over their skills in virtue of the adaptability and flexibility of their practical intentions.

This strategic aspect of skill is especially salient when it comes to open skills like those on display in team sports where performance cannot be pre-planned but must adapt to the significant variability of the action space, another team, and players. That is, deciding what to do is something that the player does in real time (even if a more general strategy has been agreed on by the coach and team) and part of what makes some players more skilled than others is that they make better decisions about which actions to perform, at which time, and in which sequence. It's important to see however, that even in closed skills like gymnastics or piano, strategic control is key to performance. This should be clear since even if the general sequence of events is pre-planned (perhaps like the general strategy that a coach may decide on for a team), precisely how the plan is formed, structured, and organized, that is, how the components of the sequence are conceived of and connected to one another, has an important impact on the way in which the skill is performed. Accordingly, action plans include more than simply an abstract description of what to do and what order to do it in. They include specific, practical specifications about the action to be performed and how that action ought to unfold. It is here that we can see strategic control as relevant both for open and closed skills.

To be as clear as possible, my position is that part of what accounts for the control of skill ought to be cashed out at the higher-order cognitive level. This is not to say, of course, that an adequate account of the intelligence of skill ought to be given exclusively at the level of strategic control. It is to say, however, that if we want to understand the intelligence of skill, part of this intelligence occurs at the level of strategic or cognitive control and, as such, we need a working account of this kind of control, if we are to have a complete account of skill. So, since strategic control makes an important contribution to skill, it is crucial to (1) make the case that higher-level cognitive features play a central role in skilled action and (2) sketch out the nature of the contribution at this level of strategic control.

\footnotetext{
${ }^{2}$ This notion of strategic control is similar in some important respects to Christensen et al.'s (2016) notion of cognitive control and also, to some extent, Pavese's (2019) conception of practical representation.
} 


\subsection{Is cognition really relevant for skill?}

On one dominant conception of skilled action, skills are automatized actions that are best when mindless. On such an account, the pinnacle of expertise is devoid of thought; it is all body and movement. As Dretske (1998) writes: "[I]n the case of all skilled actions, whether it be tying your shoelaces, playing a musical instrument, or dribbling a basketball - the mind goes elsewhere while the body performs." And John Searle asserts that "[R]epeated practice enables the body to take over" (1983, p. 150). Further, Sutton and colleagues, critiquing Dreyfus's account of skill, write of his position: "Only when one is involved, and gets a lot of practice, will the body take over and do the rest. There is then neither thinking nor awareness, neither attention nor choice: at this level of fluid performance, "an expert's skill has become so much a part of him that he need be no more aware of it than he is of his own body"' (2011, p. 89).

This is the view of skill and expertise that Montero (2016) has labeled and objected to as the "just do it" theory of skill. In philosophy, probably the most prominent defender of this kind of conception of skill is Dreyfus $(2002,2004)$ and Dreyfus and Dreyfus (1986) who emphasizes the phenomenological absence of agency in certain kinds of skilled experiences, like flow, to argue for conclusions about the metaphysical structure of truly expert performance. Such accounts are quite extreme, going as far as to deny that skilled actions are a species of intentional action. In other work (Fridland 2014), I have argued explicitly against this conception of skill as mindless. Though I will not go into these arguments in detail here, it is worth noting that Bermúdez (2017) has elegantly highlighted the inability of Dreyfus-type accounts to explain how complex actions in multifaceted domains with multiple competing affordances can remain on task and flexible in the absence of an organizing intention. And Bermúdez (2017), myself (Fridland 2014), and Wu (2015) have all also emphasized how intention must be active in skill in order to guide the selective attention required for appropriate and successful skill instantiation.

\subsection{Empirical evidence does not show that unthinking skill is best}

Still, a "just do it" position seems to be in lockstep with empirical evidence from sports psychology showing that conscious thought or deliberation can disrupt skilled action (Kimble and Perlmuter 1970; Langer and Imber 1979; Baumeister 1984; Lewis and Linder 1997; Masters 1992; Beilock and Carr 2001; Beilock et al. 2002; Beilock 2010). This sort of conception is also a seemingly natural way to account for the incontrovertible fact that during the learning process, through practice, novice actions go from being explicitly controlled in a direct and active manner to becoming automatic, such that explicit, cognitive control of each individual element of the action is no longer required once the skill has been learned and trained (Fitts and Posner 1967; Anderson 1983, 1993). So, it is worth addressing at least briefly why we should not conclude from these 
considerations that skilled actions are devoid of thought, even if we accept that skilled actions are largely automatic and can be disrupted by certain kinds of thinking or attention.

My position is that it is perfectly consistent to hold that the cognition involved in well-trained skill is different from the cognition that guides novice skill learning. And obviously, a difference in cognition doesn't imply its absence. We should notice that simply because the cognitive effort required for monitoring and controlling the step by step performance of a complex action in the early stages of skill learning is reduced when the skill becomes fully automatic, does not entail that, once learned, skills lack any substantive cognitive component.

In fact, most theories of skill posit that automatizing a procedure has the benefit of reducing the investment of cognitive resources required to guide the mechanics of movement execution precisely so that those cognitive resources can then be used for other sorts of higher-level, often skill-related tasks (Fitts and Posner 1967; Anderson 1993). For instance, once a series of piano notes has been learned to the point that they can be played automatically, the piano player can then focus on the aesthetic, expressive, or especially challenging aspects of the piece. ${ }^{3}$

On such a view, the cognitive component of skill does not disappear but, rather, shifts one level up. Of course, I have argued that the automatized motor routines constitutive of skilled action remain intelligent even after they are automatic (Fridland 2014, 2017a, b, 2019a). My point here in appealing to what I take as the orthodox position is not to endorse every letter of it but to highlight that even if we take a pretty standard line regarding the intelligence of skill, we would likely still hold that cognition plays an important role in skilled actions. In this way, the strategic level is still relevant for a full account of skill.

Another popular position regarding skilled performances promotes the idea that not only is conscious, deliberate, higher-order thought unnecessary for skilled performance but that it is, in fact, counterproductive. That is, thinking about one's performance undermines the success of that performance. As such, it is commonly held that conscious, reflective thinking interferes with and, as such, is incompatible with truly skillful performances.

Much of the research on this question involves demonstrating disruptions of skill when experts are asked to attend explicitly to specific aspects of their movements or task. For example, Beilock et al. (2002) shows that when expert golfers were asked to attend to the exact moment their club head stopped its follow-through, they performed worse than when they were asked to keep track of a totally unrelated-to-thetask auditory tone. Papineau (2013), relying on evidence of this sort, defines this specific phenomenon of degraded or disrupted performance, which he calls "The Yips," as "what happens if you start thinking explicitly about the bodily movements required for some sporting performance" (p. 4). The idea is that focusing on the execution of a well-learned motor routine interferes with its success.

We should notice that accepting the claim that attention to certain aspects of one's own movements can disrupt expert performance does not entail that consciousness

\footnotetext{
3 See Christensen et al. (2016) for more on this kind of view. See also Papineau (2013).
} 
or attention or thinking, in general, undermines successful performance. The most that we can conclude from this sort of evidence, of course, is that conscious attention or effort devoted to particular (perhaps irrelevant) aspects of the mechanics of one's own skilled movements, are counterproductive for successfully executing them. But this rules out neither the possibility that one may benefit from thinking about other aspects internal to the performance nor that focusing on strategy or other high-level characteristics of performance is important for skill.

After all, it remains a distinct possibility that thinking about particularly relevant aspects of the mechanics of a performance can lead to improvements in skill. So, while it is perhaps true that, e.g., focusing on the location at which the golf club head stops its path through space is harmful for golf performance it is still a distinct possible that, e.g., thinking through and anticipating the exact sequence of notes and specific finger movements required to play a particularly difficult piano passage helps one perform it better. This is, after all, exactly the kind of thing that has actually been shown to be beneficial for piano playing (Duke et al. 2009). Moreover, it is certainly not clear that thinking about higher-order, aesthetic, or strategic features of the performance is detrimental to the skilled action. That is, even if we accept that attention to particular aspects of performance is detrimental to skill this does not entail that skilled actions are mindless at all levels. Shepherd (2015) has argued this point to my mind persuasively, appealing to empirical evidence of improvements that result from the deliberate use of motor imagery during performance (Guillot et al. 2013). In fact, I don't think this is even what Beilock or Papineau think the appropriate conclusion from these kinds of studies should be. Like with practice and automaticity, cognitive or strategic control may be most effective when it is concerned with more global features of the task. As such, a role for strategic control in a theory of skill is hardly challenged by the fact that certain kinds of thinking about the internal mechanics of movements are bad for skill.

\subsection{Kinds of cognition in skill: strategic knowledge and strategic control}

In order to pinpoint exactly how we ought to understand the strategic aspects of skilled action control, it will be useful to draw a distinction between strategic knowledge and strategic control. Strategic knowledge, in the way I conceive of it, is knowledge about skill. ${ }^{4}$ It can be background, general, or structural knowledge that can contribute to a skill's success and determine choices about how the skill is to be performed. Importantly, the amount of strategic knowledge that an agent possesses is not necessarily proportional to how skilled that person is. For example, one can have encyclopedic knowledge about baseball batting statistics and be a very poor batsman. On the other hand, of course, that knowledge can contribute to a skilled batsman's choice of how to hit. And that will obviously have follow-on effects for the success of the batting.

\footnotetext{
4 This point tracks Fridland's (2015) distinction between knowledge how and knowledge about how.
} 
Strategic knowledge may be learned through practice but, importantly, it can also be acquired in various, non-practical ways, for example, through testimony or study. For instance, we might learn the rules of football by watching a football game and we may learn a natural progression of chords by studying music theory. We may learn great strategies for hockey defense by reading a book and we may learn the sequence of moves in a dance routine through verbal instruction. The point is that we don't need to develop strategic knowledge by actually practicing our skills. Even though, of course, we may learn these things through practice, too.

On the other hand, strategic control is meant to designate knowledge in action. Strategic control is a kind of practical knowledge. This sort of knowledge is proportional to skill level and effective in structuring, organizing, and guiding instantiations of skilled actions. As such, the more strategic control a person has the better she should be at performing her skill. It follows that as one develops strategic control, one's skilled performance will improve. However, since there are at least two other components that compose the control of bodily skill (e.g., attention control and motor control), it isn't necessarily the case that the relationship between strategic control and overall skill quality will be 1:1 (Fridland 2014, 2021). ${ }^{5}$

It will be the primary objective of this paper to identify and characterize strategic control. I will suggest that strategic control concerns the development of action schema, which are integral to skilled actions and which develop exclusively through practice. I will further suggest that practical intentions, which are commitments to action schema, are best conceived of as higher-order, motor-modal ${ }^{6}$ plans that structure complex actions by specifying the various relevant invariant, action-oriented features of the actions involved in the performance of the skill. Importantly, these plans, when instantiated, are rational, personal-level intentions despite being formulated in perceptual and motor code.

In order to specify the kind of action plans that are involved in strategic control, I'll rely on empirical evidence concerning mental practice and mental imagery from sports psychology as well as evidence highlighting the systematic differences in the cognitive representations of skills between experts and non-experts. I'll claim that, together, this evidence suggests that the intentions that structure skilled actions are practical and not theoretical, that is, that they are perceptual and motor and not abstract, amodal, or linguistic. Importantly, despite their grounded nature, these plans are still personal-level, deliberate, rational states. That is, the practical

\footnotetext{
${ }_{5}^{5}$ It's important to see here that the distinction that I'm drawing is not necessarily a distinction between propositional and nonpropositional knowledge (though, of course, it could be). In this way, it is not a distinction that is anathema to Intellectualism about know how. For instance, the Intellectualist draws a distinction between familiar kinds of propositional knowledge and propositional knowledge represented under a practical mode of presentation (Stanley and Willamson 2001; Pavese 2015). Strategic control could be seen as a way of understanding the propositional knowledge represented under a practical mode of presentation, though, as I cash out strategic control, it will be clear why I don't assimilate the Intellectualist terminology.

${ }^{6}$ By "modal" I mean sensory/perceptual. As in, relating to the sensory modalities. I use this term rather than the more common "sensorimotor" in order to avoid identifying the structures that I am concerned to spell out here with low-level or subpersonal processes, which is often how sensorimotor states are understood.
} 
intentions that specify and structure skilled actions are best conceived of as higherorder, motor-modal structures, which can be manipulated and used by the agent for the purpose of reasoning, deliberation, decision-making and, of course, the actual online structuring and organizing of action.

Before proceeding, it is critical to make a note about the methodology that I will employ in many of the following arguments. Rather than taking independent lines of evidence and drawing specific conclusions directly from those independent research programs, I will combine empirical research of various kinds with theoretical considerations in order to provide what I see as the most plausible, coherent, and potentially powerful interpretation of the evidence, all things considered. In this way, my position will synthesize a large amount of research in order to provide a view of strategic control. In this way, mine is an abductive approach, attempting to do justice to the totality of the relevant evidence. So, though various objections can of course be raised to individual claims or interpretations, as they always can, it is critical for the reader not to take one stream of evidence in isolation when my argument relies on combining evidence to construct and support the best overall picture of the strategic control involved in skilled action.

\section{Mental practice, physical performance, and strategic control}

In this section, I'd like to propose that the literature on mental practice may be particularly helpful for understanding the strategic dimensions of skill. Mental practice is commonly understood as the use of mental imagery to rehearse a task in one's mind, without performing the associated physical movements. So, why would mental practice be useful for understanding the strategic dimensions of skill? Namely, because it is widely agreed that mental rehearsal using perceptual and motor imagery is especially relevant for developing the cognitive aspects of skill. In fact, many scientists hold that the more cognitive complexity a skill involves, the more effective mental practice should be Feltz and Landers (1983), Driskell et al. (1994), Hanakawa et al. (2003), Lotze and Halsband (2006), Iseki et al. (2008) and Gentili et al. (2010). Moreover, fMRI studies investigating the underpinnings of mental practice support the view that rehearsal using mental imagery specifically engages neural areas that are usually associated with certain kinds of higher-order cognitive tasks (Pascual-Leone et al. 1995; Langheim et al. 2002; Guillot et al. 2009; Hanakawa et al. 2003, 2008). From a common sense perspective, too, it makes sense that the aspect of skill that mental practice is most effective for developing is not the lower-level, sensory and motor components of skill, which require actual ongoing sensory feedback for learning since such feedback is unavailable without actual movement.

In addition, we see that the mental imagery of skilled agents differs systematically from that used by novices. That is, expert's imagery is more vivid, more accurate, more useful, and more structured than that of novices, suggesting that this higher-order aspect of skill develops with practice (Lotze et al. 2003; Reed 2002; Schack and Mechsner 2006; 2010; Schack et al. 2014). Importantly, this is not to say that only the higher-order features of skill improve with mental practice but it 
is to highlight that mental practice is especially effective for refining these aspects of skill. Moreover, if we think that mental and physical practice are two ways of achieving the same ends, that is, if we think of mental and physical practice as developing and refining the same basic structures that support skillful action, as I think we should, then we can learn about at least some aspects of physical practice by focusing on its mental cousin.

\subsection{Mental practice: neurological evidence}

So, let us turn to mental practice. There are two particularly curious things about mental practice that are worth pointing out. First, the imagery involved in mental rehearsal seems to involve the same cortical regions and processing profiles that guide actual action (Decety et al. 1992; Cohen et al. 1996; Kosslyn 1999; Kosslyn et al. 2006). This fact goes some way in explaining the second surprising fact about mental practice-that it is remarkably effective for improving actual performance (Feltz and Landers 1983; Driskell et al. 1994; Jeannerod 1994; Guillot et al. 2009; Hanakawa et al. 2003, 2008; Madan and Singhal 2012; Schack et al. 2014). That is, rehearsing a gymnastics routine or playing a piano piece in one's mind has significant benefits for the actual execution of the skill. Sometimes, mental practice is as effective as physical practice. More often, mental practice is pretty effective in improving skill but not quite as effective as physical practice or a combination of the two (Pascual-Leone et al. 1995; Guillot 2009; Guillot et al. 2010; Gentili et al. 2006; Gentili et al. 2010; Madan and Singhal 2012 (review); Bernardi et al. 2013). As I said, the first fact about mental practice could go some way in explaining the second. That is, if imagery and action involve the same neural and functional states then mentally practicing would refine the same representational states or structures that underpin actual action, thus laying the groundwork for improvements of real performance. But why should we think this is the case?

First off, there is a significant, established body of neural evidence indicating that mental imagery and actual action are underpinned by the same cortical areas (for a comprehensive list of relevant studies see Kosslyn et al. 2006, Appendix). For instance, imagining walking across a room and actually walking across a room involve activity in the same brain regions. Imagining waving your hand or swimming or eating a bowl of spaghetti, etc. involve many of the same brain regions as actually doing these things. ${ }^{7}$ This is the case for motor imagery and visual imagery and presumably for other sensory modalities as well. In short, from a neural perspective, actual action and imagined action exhibit significant cortical similarity. Of course, this fact alone doesn't entail that actual and imagined action involve the same functional and representational structures but in combination with evidence of common processing principles and constraints and deficits reviewed below, this strikes me as an inference to the best explanation.

\footnotetext{
${ }^{7}$ I should note that this is a generalization from the actions that are possible in an fMRI scanner.
} 


\subsection{Mental practice, performance principles and constraints}

A significant body of empirical evidence suggests that imagined and performed actions share not only a neural substrate but that both phenomena are governed by the same processing principles and constraints. For instance, it is well known that imagining performing an action and actually performing the action are subject to similar temporal constraints. For instance, the time it takes to scan a visual image in imagination and to actually scan an object with one's eyes both depend on the distance that needs to be scanned (Kosslyn 1973; Kosslyn et al. 1978; Denis and Cocude 1989). Imagining signing one's name and actually signing one's name take about the same amount of time and both depend on the hand or "hand" used and the size of the signature (Decety and Michel 1989). The time it takes to imagine walking to various spots depends on their proximity as would the actual time it would take to walk to them (Decety et al. 1989). The time it takes to rotate a three-dimensional object in one's imagination depends on the angle of rotation, just like the time it takes to actually rotate an object depends on how far it needs to be rotated (Shepard and Metzler 1971). It is also well established that motor imagination, like action, adheres to Fitt's law, where speed and accuracy trade-offs are integral to performance speed and success (Georgopoulos and Massey 1987; Decety and Jeannerod 1995; Sirigu et al. 1995, 1996; Crammond 1997). So, for instance, imagining an action that requires a high degree of accuracy, for instance, parking a car in a small garage space, takes longer than imagining an action that requires less accuracy, for instance, parking that same car in an empty parking lot. And the same is true, of course, for ordinary action, too.

\subsection{Mental practice and motor deficits}

Further, Jeannerod (1994) has argued that not only does mental imagery share a cortical substrate and functional profile with physically performed action but that these similarities are best interpreted as implying that the motor representations involved in motor imagery are the same informational states used for guiding actual instantiations of action. That is, the representations that govern motor imagery are functional for planning, structuring, and guiding live, online action execution. This hypothesis is supported not only by the neural evidence for overlapping cortical systems and psychological evidence of shared performance profiles but also by evidence that deficits in motor imagery, especially at the level of organization and planning, and deficits in performance are somewhat correlated. For instance, it is well known that motor imagery, like actual movement, can be affected in patients with Parkinson's Disease (PD) (Dominey et al. 1995; Yágüez et al. 1999; Thobois et al. 2000) and also in hemiplegic patients (Decety and Boisson 1990). Additionally, lesion studies have produced evidence of numerous overlapping deficits between action execution and action imagination (See Decety 1996 for review). Lastly, it is a distinct possibility that patients with ideomotor apraxia, who have difficulties imitating complex movements and often have difficulty reconstructing the sequence of movements 
required for complex tasks also have difficulties both in imagining complex actions (Ochipa et al. 1997) and recognizing them (Heilman et al. 1982).

In combination with strong neural evidence of overlapping cortical regions in motor imagination and actual action, the symmetrical constraints and processing principles of imagination and action, and preliminary evidence of symmetric deficits in imagery and action in ideomotor apraxia and PD, make it clear that motor imagination very likely involves many of the same cognitive structures as the physical instantiation of action. This seems to me to be the best way to make sense of the totality of evidence presented above. Importantly, this also makes a focus on mental practice interesting for learning about the inner workings of physical practice and its products.

Of course, if mental imagery rehearsal is similar in the relevant ways to actual practice, (as this empirical evidence seems to suggest) then, assuming there is more to learn through practice than a kind of low-level readjustment of sensorimotor thresholds, which there seems to be, we should expect that the products of mental practice will help us to isolate those more cognitive or strategic aspects of control. This is particularly important for my purposes since identifying and understanding control is central to understanding skill. Accordingly, my hope is that we can learn about the nature of strategic control by looking at the learning that takes place through mental practice. Assuming this is pretty much correct, in the next sections, I'll use experimental evidence from studies of mental practice to make claims about the strategic control involved in skilled action.

\section{Strategic control and practical intentions}

So, what exactly do we learn through mental practice and how is this related to skill in general? I suggest that what we learn through mental practice, primarily, is strategic control. I'll claim that strategic control refers to practical intentions that are appropriate, effective, and flexible in virtue of the action schemas that constitute them. Accordingly, I'll claim that the flexibility and appropriateness of action schemas is exactly what gets refined through practice, either mental or physical.

As I've argued elsewhere, we can distinguish between general and practical intentions, where general intentions specify the general goal or end of the task and practical (instrumental) intentions fill in the means or way of achieving that goal (Fridland $2019 b)$. When it comes to skill, the most relevant kind of intentions are the practical ones, since differences at the level of practical intention are likely to reveal differences in skill level whereas both skilled and unskilled agents could easily share general intentions. For example, both a skilled and unskilled diver may plan to do a front tuck into the water but the way in which each actually plans to do this differs in important ways between the two.

Unsurprisingly, then, it is precisely at the level of practical intention, that I think mental practice has an impact on strategic control. I propose that, with practice, the instrumental plan that an agent uses to achieve her general intention becomes formulated, organized or structured in such a way that it can be flexibly and appropriately modified and adjusted to easily and effectively achieve task success. The 
structure that encodes and guides such a plan, I call an action schema, and I will discuss in some detail below how we are to understand such a structure. For now, it is important simply to say that practical intentions are commitments to action schemas. When those commitments are instantiated, an agent has formed a practical intention. In short, through practice, an agent develops strategic control by developing the right kinds of action schemas. The agent can then use those actions schemas to token practical intentions as appropriate. As such, practical intentions can guide action effectively because they are composed of action schemas, which have been learned through practice. Importantly, since the action schemas that constitute a practical intention are developed through practice, they are not the kinds of plans that will be shared by experts and novices alike.

Practical, embodied intentions, on the account I am offering, are the instantiated higher-order, modal-motor structures that encode specific invariant features of actions and guide actions in virtue of encoding this information. In this way, actions schemas have two directions of fit; they are both informational states and control states. The invariant features they encode are usually combinations of complex action elements, which are specified in in terms of motor commands and expected sensory outcome pairs. What I have in mind is very much in line with what Mylopoulos and Pacherie (2017, 2019; from hereon M\&P), following Schmidt (1975, 2003) have called "motor schemas". As they explain:

According to schema theory, motor schemas are both repositories of information and control structures. They are internal models or stored representations that represent generic knowledge about a certain pattern of action and are implicated in the production and control of action.... The generalized motor program is thought to contain an abstract representation defining the general form or pattern of an action, that is the organization and structure common to a set of motor acts (e.g., invariant features pertaining to the order of events, their spatial configuration, their relative timing and the relative force with which they are produced" (M\&P 2017, p. 330).

On the account I' $m$ offering, however, there is one significant difference between motor schemas and embodied, practical intentions. Most importantly, the informational states that I think develop as a result of mental practice are personal-level representations that an agent can access, manipulate, commit to, and use for planning, decision-making and reasoning. That is, they are agent-level structures, whereas M\&P's motor schemas are subpersonal, unconscious states that are not directly responsive to or involved in practical reasoning and agent-level thinking. ${ }^{8}$

\footnotetext{
8 According to M\&P, "the motor representations that guide specific actions are instantiations of motor schemas" (M\&P 2017, p. 330). But as M\&P describe them, "Rather than being the inputs and outputs of practical reasoning processes, they [motor representations] are the inputs and outputs of rapid sensorimotor computations. Rather than being subject to norms of practical reasoning they are subject to a set of biomechanical and motor rules. Rather than being personal-level representatons, they are subpersonal representations. Rather than functioning under conscious control, they function largely automatically (M\&P 2017, pp. 322-323).
} 
Instead, for M\&P motor schemas are triggered, or activated by their associated executable action concept (M\&P 2017, 2019). This difference makes all the difference since on the account I am developing, modal-motor informational structures can themselves function as intentions - that is, states that we can commit to and with which we can plan and guide action in virtue of the informational relations (spatial, temporal, biomechanical and predicted) which are encoded by them. That is, these structures are not merely associated with or triggered by concepts but are themselves, in virtue of their structural and informational relations, involved in thought and reasoning. In order to differentiate my view from that of M\&P, while still doing justice to the important influence that their thinking has had on my own, I will call the informational structures that can be used to plan and guide action, that is, the practical intentions that ground strategic control, "action schemas". In this way, I hope to signal the agent-level nature of action schemas, and contrast them with M\&P's "motor schemas". It's also important to note that actions schemas differ in significant ways from M\&P's notion of an executable action concept (M\&P 2017) in that actions schemas are not concepts connected to lower-level motor schema but are themselves personal-level structures, the manipulation of which constitutes thinking.

Before moving on, it is worth noting that in the recent philosophical literature on practical intentions, especially in the literature addressing what has become known as "the interface problem" (Butterfill and Sinigaglia 2014) there have been several proposals that are very much in the spirit of my current suggestion-that motor and perceptual states are accessible to the agent and play a role in setting intentions. For example, Brozzo (2017), in arguing against Pacherie's (2006) characterization of M-intentions has claimed that the motor imagery involved in motor intention, if it is to qualify as a genuine intention, should be accessible to the agent, integrated with propositional contents, and meet strong rationality requirements. In a similar vein, Shepherd (2019) has proposed that practical intentions specify outcomes both propositionally and motorically. And that the motoric element of practical intention should be thought of as conscious, agent-level, and involved in practical reasoning (Shepherd 2018). Moreover, Ferretti and Caiani (2019) have also advanced what they call the "same format thesis" where both motor representations and practical intentions share a perceptual-motor code, which allows them to interface without facing the problem of translation.

Though my account is situated firmly within the same camp as these proposals (and I take this to be a good thing-that many like-minded philosophers are converging on a common answer to a difficult question), I should note that the current proposal differs from the accounts on offer in a few ways. The most relevant, I think, is that it specifies in some detail what a practical intention, coded in perceptual and motor code and available to the agent for reasoning and planning, actually consists of. That is, I give a substantive proposal for not just the function but also the structure and content of such an intention. I should also note that in contrast to Shepherd's (2019) claims that intentions have both motor and propositional components, the account I offer emphasizes bona fide reasoning at the perceptual and motor level. That is, on the account I offer, intentions can be thought of not only as having contents in two different codes but as states that are themselves percepuo-rational and which can enter into personal-level planning, reasoning and deliberation without the 
support or accompaniment of propositional thought. I take it that this is a small step further than Shepherd has gone.

Another point I'm concerned to emphasize is that it is key to understand that action schemas encode not only features like sequence, timing, relative force, etc. but also prediction or anticipation of expected action outputs. This forward looking informational aspect of action schemas allows us to explain why improvements in anticipation are central to the benefits of mental practice and connect this account up with ideomotor theories of action (Prinz 1997; Hommel 2009, 2015). This predictive element also helps us to connect action schemas to intentions or plans, since anticipation is a sign of personal-level knowledge and planning. In the following section, I will proceed through various empirical considerations that suggest that this kind of higher-order, motor-modal, simulative forward model construed in terms of action schemas, is the best way of thinking of practical intentions and the strategic control that results from practice.

It's important to see why we should think of practical intentions as somewhat intermediate between high-level abstract, amodal representations and low-level sensorimotor processes. My claim is that practical intentions involve structures grounded in perception and action but that these are not low-level, subpersonal, associative states. ${ }^{9}$ In the way I am conceiving of the practical intentions involved in strategic control, they are personal-level, higher-order, motor-modal structures. Further, they can be targeted by deliberate manipulation and conscious control and they can be involved in agent-level processes such as counterfactual reasoning, and decision-making.

Practical intentions are rational states insofar as they are means-ends coherent, and consistent with beliefs and desires. For all that, they remain representations of perceptual and motor systems. I should add that I am not simply asserting here that practical intentions involve embodied concepts (Barsalou 2008, 2010). I am claiming that the intentions that we use to plan, specify, and guide skilled actions are effective in virtue of the shape and configuration of their modal-motor, informational structures. ${ }^{10}$ That is, the claim here is not that we use concepts to reason and those concepts happen to be modal. The claim is that, at least sometimes, we reason by manipulation, perhaps via simulation (Currie and Ravenscroft 1997; Prinz 2004), of the structural relations that constitute action schemas. That is, we use the information gathered through the manipulation of action schemas, to guide decisionmaking, counterfactual reasoning and action.

\footnotetext{
${ }^{9}$ It is worth noting that associations are thought to be semantically insensitive to logical form (see Nanay (forthcoming) and involuntary (Mandelbaum 2016). But practical intentions, on my view, are neither.

${ }^{10}$ I take this claim to be in a similar spirit to Shepherd's (2018) proposal concerning the practical reasoning that is possible with intentions that have a mixed representational formats (both propositional and motoric).
} 


\section{The practicality of practical intentions}

Why think of mental practice as yielding practical, motor-modal representations of strategic control rather than more general, abstract or amodal knowledge that can be applied to skills? That is, why not think that what we learn through mental practice is mostly knowledge about what needs to be done in order to perform the skill? That is, knowledge about the way in which the skill should be approached, or knowledge of the general sequence or structure of movements that need to be performed in order to execute the skill? There are two reasons to avoid thinking of the products of mental practice as a kind of abstract or theoretical strategic knowledge. The first follows from evidence concerning who benefits most from mental practice (i.e., experts) and the second follows from direct neural evidence about the specific network of brain regions involved most in mental practice (i.e., higher perceptual and motor areas). Together, these considerations combine to make the most plausible conception of strategic control essentially a practical one. I will address each in turn.

\subsection{Mental practice: the expert and the novice}

The first reason to avoid thinking of the products of mental practice as a kind of general knowledge about skills follows from research showing that experienced agents benefit from mental practice more than novices (Richardson 1967; Mahoney and Avener 1977; Driskell et al. 1994; Hardy and Callow 1999; Lotze et al. 2003; Madan and Singhal 2012) That is, both when looking at who uses mental practice and whose performance improves most from the use of mental practice, it is clear that experts are the main beneficiaries. But how does this help us to understand the nature of what gets learned through mental practice? The answer follows from an understanding of what kind of knowledge is most useful at which stages of learning.

We should notice that, if mental practice were most effective for generating and refining knowledge about skilled actions then it would be in the early stages of learning where such practice would be most effective. After all, it is at the early stages of skill learning where we learn the basic goals, sequence, and form of action required for the performance of a skill. That is, it is in the early stages of skill learning that we learn what needs to be done in order to perform the skill. Accordingly, if this was predominately what we learn through mental practice then mental practice should be especially fruitful for novice learners. Picture, after all, what often happens at a first practice or lesson: students stand around and watch as a coach or teacher explains and sometimes demonstrates what needs to be done in order to, e.g., do a cartwheel or swing a bat or play a series of piano notes. That is, the general instruction involved in skill is most relevant for early learning.

However, a broad set of empirical evidence confirms that it is not the novice but indeed the experienced, already somewhat or very skilled agent that benefits most (and most often uses) mental rehearsal. That is, it is precisely not in early learning that mental practice is most effective. This means that whatever gets learned and refined through mental practice it isn't primarily general knowledge about the skill. 
I should note that this is not meant to be an argument against the possibility of an expert gaining knowledge about her skill from mentally practicing it. The expert may very well learn such knowledge. The point, rather, is that this is not primarily the type of knowledge implicated in mental practice. If it were general knowledge about a skill gained from mental practice one would expect, at the very least, both the novice and the expert to both benefit equally. Though, as I argued above, it seems reasonable that the novice would benefit more. In either case, though, if it were knowledge about the skill that were learned through mental practice, it seems particularly surprising that the expert would benefit more.

More speculatively, it seems that whatever it is that makes mental practice effective for experts most likely concerns knowledge that has been acquired through experience. A plausible conjecture is that real-world experience develops knowledge structures relevant for guiding action as it unfolds. It is this kind of experience-based knowledge that gets refined by experts in mental practice. Since novices have not yet acquired these kinds of experiential representations, or what I'm calling, action schemas, or they have not acquired them with sufficient accuracy, we have an explanation of why it is that novices benefit least from mental practice. It is, after all, this kind of experience-based knowledge that novices lack and that experts have and which can explain the difference in the effectiveness of mental practice for each.

If this is right, then we can say that mental practice refines the perceptual and motor representations that are involved in the actual guidance of action. That is, imaginative rehearsal works by refining those psychological structures that have been acquired previously through experience and which are central to the implementation of skill. Structures that I am calling action schemas. Without these structures, however, that is, without the existence of informational structures that are involved in guiding the implementation of the skill in question, there is nothing for mental practice to work on. That is, mental practice doesn't have the control structures to work with. And this is why mental practice is not as effective in the early stages of skill acquisition as in later stages of expertise.

\subsection{Practical intentions: neural evidence of higher-order motor-modal control}

Further, evidence concerning the neural structures involved in mental practice help justify a positive conceptualization of the strategic products of practice as experiential, higher-order, modal and motor structures. Importantly, we should note that the experiential representations are perceptual and motor but not subpersonal or low-level kinds of states. Several studies investigating the cortical systems involved in mental practice using modal and motor imagery converge on a network of brain areas most centrally implicated in these phenomena. The general consensus is that the areas most relevant for and reorganized by mental practice are those that we can think of as "higher perceptual and motor areas". These areas include premotor and parietal areas, SMA and the cerebellum (Hanakawa et al. 2003, 2008; Langheim et al. 2002; Pascual-Leone et al. 1995). That is, direct evidence of neural activity during mental rehearsal and comparisons of mental practice to actual practice consistently point to cortical regions in higher 
perceptual and motor areas as the location most relevant for mental practice and imagistic rehearsal. This is not to say that executive areas are not relevant for mental practice (I've argued above that they are) nor that lower-level activation is not often observed (I've said these are often relevant too). It is only to say that at the heart of understanding changes and improvements that result from mental practice and, thus, the development of strategic control in skilled action, seem to be the higher perceptual and motor areas of the brain. Combined with considerations above regarding the increased benefits of mental practice for experts over novices, this helps us to fill out a picture of mental practice as the refinement of higher-order, motor-modal structures that organize complex actions by encoding neither fully abstract, conceptual or linguistic representations of the skill nor low-level primary sensory refinements but, rather, grounded, invariant, structural features of the skill.

This much should be clear since, if what was learned through mental practice was mostly of the strategic knowledge variety, that is, general knowledge about the skill, its shape or form, then we should see improvements in skill learning most pronounced for novices and we should also see mental practice related most closely to executive cortical regions. That we see the neither of these things should lead us to the conclusion that mental practice is most relevant for producing changes in structures or representations that have been acquired through experience, likely in higher modal-motor areas.

It's important to note, also, that we are dealing with higher-order modal-motor areas and not primary ones. After all, because mental practice lacks actual sensory feedback, which would seem to be required if mental learning were to be effective at the lowest sensory level, it isn't likely that the learning that results from mental practice targets the most basic, primary sensorimotor representations. Moreover, we can further be assured that the changes that result from mental practice are not primarily low-level adjustment of sensorimotor thresholds since we see both that mental rehearsal doesn't always involve activity in the lowest-level, sensorimotor processing regions within the primary motor cortex (Dechent et al. 2004; Gerardin et al. 2000; Hanakawa et al. 2003, 2005, 2008; Naito et al. 2002) and that at least in some cases primary or low-level perceptual regions are not necessary for mental imagery. We know this because some lesions in, for instance, primary visual cortex, have no deleterious effect on imagery abilities (Chatterjee and Southwood 1995; Bartolomeo et al. 2013; Bridge et al. 2012; Brogaard and Gatzia 2017). This is not to say that many times primary areas are not active during imagery but only to say that this activation is not necessarily central to the imaginative process in general. As such, since mental practice relies on mental imagery, it is the cognition at the level of mental imagery, which seems most relevant for understanding improvements that result from mental practice. But since mental practice seems to involve lower sensory areas only contingently, it is very unlikely that what is learned through mental practice is primarily of this nature. As such, when we think of the products of mental practice we seem to be honing in on intermediate level states: neither primary sensory representations nor global, executive ones. What we are dealing with, then, are embodied, action-guiding states, that structure skills perceptually and motorically but with some degree of abstraction and generality. 


\section{Are action schemas really personal-level structures?}

Lastly, its crucial to notice that mental practice is a person-level, agential, deliberate phenomenon. It involves conscious initiation, attention, and control over one's mental rehearsal. Mental practice can be directed and redirected in deliberate, agentguided ways. As such, we are again faced with evidence that mental practice, despite involving perceptual and motor representations is not best construed as a low-level, inaccessible, supbersonal process. In fact, quite the opposite is true: mental practice involves embodied, motor-modal representations, which are personal-level states subject to deliberate control and modification as well as integration with and responsiveness to the broader epistemic and psychological states of the agent. It is in this way that we have representations that are both perceptual and rational.

We should note, further, that this way of conceptualizing the strategic control central to skill challenges a widely accepted picture of the mind. After all, philosophers often categorize the mind into either sensory or cognitive states or processes. Sensory or perceptual representations are often considered to be low-level, subpersonal, modular, bottom-up causal states that are physical or bodily. On the other hand, cognitive processes are conceived of as conceptual, abstract, amodal, rational, conscious or consciously accessible, top-down representations that enter into personallevel reasoning and deliberation. The way that I've formulated strategic control cuts across these distinctions by forwarding the existence of higher-order representations that are perceptual in nature. That is, my proposal regarding strategic control posits essentially perceptual and motor informational and organizational structures that are personal-level and rational. That is, the higher-order motor-modal representations that are key to strategic control enter into various cognitive processes like counterfactual reasoning, and decision-making, probably via some kind of simulation, and which remain consistent with beliefs and desires and means-end coherent.

To end, I'll review three considerations that justify my proposal of the action schemas that are refined through mental practice as personal-level structures. First, there is the fact that mental practice is a deliberate, reflective, personal-level phenomenon. Second, is evidence concerning improvements in anticipation that result from mental practice and, third, I'll present evidence from first-person reports of experts that suggests that the epistemic structures that experts use to guide their skills differ in systematic ways from those of novices.

\subsection{Mental practice as agent-level imagistic rehearsal}

The first thing to notice, and perhaps the most obvious, is that mental practice is achieved via the manipulation (perhaps through simulation) of action schemas. This manipulation of the action schema is something that the agent herself does and the action schemas are sensitive in semantically coherent ways to the goals and efforts of the agent. That is, the imagery involved in mental practice is something that the agent herself initiates, manipulates, and remains aware of throughout her mental rehearsal. After all, at the heart of our understanding of mental practice, lies an assumption that the agent herself evokes conscious mental imagery of a specific task 
or skill and that the practice proceeds by way of her deliberately manipulating that task or skill in imagination. Sometimes, mental rehearsal requires that agents follow quite specific instructions or focus on a particular aspect, speeding up or slowing down, the technique that they are practicing. That is, agents not only initiate the relevant mental imagery but also direct or guide that imagery in specific ways. In connection with this, we also assume that the agent is aware of her imagery-she has access to the way it appears and feels and can easily report on it.

Of course, this does not mean that there are no constraints on what can be imagined or how mental imagery can be manipulated. Quite the opposite, actually, is the case: there seem to be clear limits on what people can imagine and also on the ways in which they can manipulate what they imagine in their mental rehearsals (Parsons 1987; Vargas et al. 2004; Fourkas et al. 2006; Borst et al. 2011). In the case of skill, I'd suggest that limits on the nature and transformation of mental imagery results from the actual shape and structure of the motor-modal representations which ground mental practice, and which, as I've argued, have been acquired through experience and are also involved in the guidance of actual action. Accordingly, there should be things that one cannot imagine or cannot imagine in a great amount of detail, or can only imagine with a great deal of difficulty because those transformations are in tension with the structure of action schemas that ground the very imagery that one is using and manipulating in mental practice. Still, despite having some limits on the degrees of freedom available to imagination, mental practice remains solidly something that the agent does. As with physical action, we do not require universal, unhindered freedom to attribute agency. This itself is good reason to think of action schemas as personal-level representations.

\subsection{Mental practice, anticipation, and a connection to declarative knowledge}

A second reason to think that action schemas are best construed as personal-level structures comes from empirical evidence suggesting that an important benefit of mental practice is improved anticipation of action. Combining this finding with evidence of anticipation as an explicit, personal-level, declarative phenomenon gives us another reason to think of the action schemas that are refined through mental practice as practical plans that are available to the agent for reasoning and control.

A nice example of the kind of improvement in anticipatory movement, which results from mental practice can be seen in a study by Bernardi et al. (2013). When studying the effects of mental practice on skilled piano performance, Bernardi et al., found that mental practice using acoustic and motor imagery induced improvements in both movement velocity and movement anticipation (see also: Keller and Koch 2006, 2008; Keller et al. 2010). That is, piano players who engaged in a proscribed regimen of mental practice developed an earlier peak of movement velocity (that is, the movement was executed earlier — not just faster), they benefited from a clear prearrangement of the wrist (in expectation or anticipation of the following notes that would be played by the fingers), greater coordination of the two effectors involved (the wrist and the fingers) - that is, with practice, the movements of fingers and wrist did not just co-occur but developed a pattern of co-articulation that optimized 
the movement. This pattern is attributed to improvements in anticipation and preparation of the subsequent movements in the practiced sequence of notes.

What I'd like to suggest is that this kind of anticipatory benefit that improves movement dynamics is likely the result of improvements to the practical plan governing action. That is, improvement of anticipation that results from mental practice results from a more accurate and better-organized representation of the plan specifying the skilled action. This is a plausible interpretation since anticipatory movements are linked with declarative knowledge and explicit representation of action. Specifically, when a sequence is learned explicitly, agents will shift from a reaction time mode to an anticipatory mode of action and response initiation (Ghilardi et al. 2003, 2007, 2009). As such, "correct anticipatory movements constitute a reliable measure of explicit learning". Since my contention is that practical intentions are embodied, personal-level plans, improvements in movement anticipation support the general picture of practical intentions as explicit modal-motor plans that guide actions and are developed as a result of mental practice.

\subsection{Cognitive representation of action}

One last consideration which counts in favor of thinking of improvements in skill at the strategic level as changes to practical, personal-level, motor-modal plans, i.e., changes in the action schemas guiding skilled action, comes from a research program that has been developed by Thomas Schack. In a series of studies (Schack 2004a, b, 2010, 2012; Schack and Mechsner 2006; Schack and Ritter 2009; Schack et al. 2014) has shown that there are systematic differences in the cognitive representation of skilled actions between experts and non-experts. This is done through a method called SDA-M (structure-dimensional analysis-of mental representations), which is used to analyze the complex cognitive representations that agents have of their skilled actions (Schack 2004a, 2010). The method begins by presenting participants at different levels of skill with photographs capturing time-slices of the most basic action elements composing the skill, elements that Schack calls Basic Action Concepts (BACs). The initial segmenting of the action and identification of BACs is done through a combination of biomechanical methods of functional movement analysis, interviews, and experimental Reaction Time (RT) studies. Participants are then asked to judge how "functionally close" various pictures depicting the sequence elements of the skill are to one another. Specifically, a BAC picture is presented as fixed on a screen while the other BAC images are shown and individual BACs are highlighted. Participants then have to decide on the functional proximity of the highlighted BAC to the fixed BAC. That is, participants must identify which of the BACs would be closer or further apart in the sequence of skill execution. Next, "a hierarchical cluster analysis is used to transform the sets of BACs into a hierarchical structure. Third, a factor analysis reveals the dimensions in the structured set of BACs and, fourth, the cluster solutions are tested for invariance within or between groups" (Schack et al. 2014, p. 3).

To see more precisely how the method works, let us start with an example. A tennis serve, for instance, will consist of 3 distinct action phases that incorporate 11 
BACs. The phases are the preparation, impact, and final swing. And those phases consist of various basic action elements, BACs, such as the ball throw, bending the knees, bending the elbow, hitting point, and follow through. The participants would then have to respond by comparing the functional proximity of various stages of the serve. E.g., they would have to say how close the ball throw is to the bending of the knees and then to compare the ball throw to the hitting point, and so on.

Now, when asking skilled and unskilled agents to evaluate the degree of proximity between BACs, Schack has found systematic differences in the organizing knowledge of experts and novices. Expert representations have a distinct hierarchical structure, they are well matched for the actual biomechanical demands of the task, there is a large amount of similarity between expert responses, and, lastly, those responses are based on deep functional features of the movements. In contrast, the novice understanding of the skilled action is not clearly structured into phases, the BACs are more or less flat, the representations are not well-matched for the actual biomechanical constraints of the task, there is a lot of diversity between the judgments of novices, and the judgments are based on superficial features of the task.

The first thing to notice is that the mental representation of movements are structured in much the same way as actual movements. That is, clusters of action and mental representation of action are structurally complex, spatially distinct, temporally ordered, etc. Further, it's important to note that mental representations of the kind Schack explores are closely tied to performance. That is, agents with more accurate, more hierarchically structured representations of the skill are those who are best at performing the skill. Strikingly, we see improvements in observationbased structural judgments about skills not only as a result of actual physical practice but with mental practice as well (Schack et al. 2014; Velentzas 2010). That is, after rehearsing one's own performance using mental imagery, we see clear improvements in the structural representation of the skill in question. On the view I'm advancing, this result of mental practice helps us to hone in precisely on the strategic control that develops with skill learning. The strategic control that I've suggested functions as the practical intention guiding the skilled action.

This research is important because it helps us to see that improvements of skill are often accompanied by more hierarchically organized and biomechanically accurate representations of the practiced action. So, if experts and novices have clear, systematic differences in their representations of actions and those representations are used in guiding the planning and execution of the action, as motor schema theory posits and as I've argued above, then we can see that skilled and unskilled agents possess different practical plans organizing their skilled actions. That is, experts and novices have distinct practical intentions or action schemas governing their skills. To be clear, my suggestion is that if we accept that there are structures like action schemas that both represent and guide action then the cognitive representations that Schack probes are plausible candidates for those structures. In short, if we accept that action schemas are structures that play the role that I've suggested in skilled action then it is very likely that what Schack examines through the SDA-M method is the change in action schemas that develops with expertise. 
Further, it's important to notice that, according to Schack, the SDA-M method is better able to probe the action-oriented knowledge of agents than introspective techniques since it is action-focused rather than self-focused. ${ }^{11}$ That is, the answers subjects give concerning skill structure and organization are in response to specific explicit instructions, conscious perceptions, and personal-level judgments but they are not self-reports. After all, the domain of inquiry and focus is the skilled action itself and not the agent or her conception of the skill. As Schack writes:

BACs do not refer to behavior-related invariant properties of objects, as in the case in basic object concepts, but to perception-linked invariant properties of movements. According to the cognitive action architecture approach (Schack 2010), mental representations are though to comprise of such presentational units (i.e., BACs) and their structural relations to one another... Various methods facilitate the study of knowledge-based mental representation of movements in LTM (for an overview, see Hodges et al. 2007). However, most of them focus on explicit knowledge and are non-experimental (e.g., interviews, questionnaires, paper-and-pencil tests). As an experimental method that avoids introspective statements, Schack (2004a, 2010) introduced the SDA-M method. This method provides psychometric data on mental representations of complex movements and as such permits investigating the status and change of structures of mental movement representations" (Schack et al. 2014, p. 2).

Still, its crucial to emphasize that it is personal-level judgments that allow Schack to reconstruct the agent's representation of a skilled action. That is, novices and experts view pictures and make judgments about how the time-slice pictured is related to other specific portions of the skill. The method assumes that agents have access to the scene that they are viewing and also to the judgments that they are reporting. The judgments are not about oneself and thus they are not introspective judgments but nonetheless the judgments are provided by agents based on their own perceptions and understanding of the skill.

As such, they are clearly personal-level judgments. Accordingly, we have reason to not only think that action schemas, that is, motor-modal practical plans that guide skill, improve with practice but also to conceive of these plans as accessible to the agent for reasoning, judgment and deliberation. These practical plans, as I've construed them, are plans of the agent and not of a subsystem of the agent. And it seems to me that the considerations regarding the agentive nature of mental practice coupled with empirical evidence concerning the anticipatory improvements and changes in cognitive representation that result from mental practice all point to the same place: action schemas are practical, motor-modal, personal-level plans or

\footnotetext{
11 In this way, Schack is clear that this method is not primarily concerned with knowledge about the skill but with the practical, perceptual-cognitive representations that agents use to organize their skills. See especially, Schack and Mechsner (2006, p. 77).
} 
intentions which improve through practice and are responsible for the strategic control characteristic of skilled action.

\section{Conclusion}

To conclude, I have argued that the best way to understand the strategic control of skilled action is by appeal to action schemas that are learned through practice and which constitute practical intentions, when an agent commits to them. I have relied on evidence from the literature on mental practice to argue that action schemas are information and control structures that are both perceptual and rational in nature. I have argued that such structures are both personal-level and embodied and that they guide skill insofar as they contain a crucial anticipatory component. This is an unusual hypothesis that cuts across the orthodox categories with which we commonly sort mental representations. As such, I see this as the fist step in exploring and establishing the nature, function, and payoff of such control structures.

Acknowledgements Funding was provided by Templeton World Charity Foundation (Grant No. TWCF0262).

Open Access This article is licensed under a Creative Commons Attribution 4.0 International License, which permits use, sharing, adaptation, distribution and reproduction in any medium or format, as long as you give appropriate credit to the original author(s) and the source, provide a link to the Creative Commons licence, and indicate if changes were made. The images or other third party material in this article are included in the article's Creative Commons licence, unless indicated otherwise in a credit line to the material. If material is not included in the article's Creative Commons licence and your intended use is not permitted by statutory regulation or exceeds the permitted use, you will need to obtain permission directly from the copyright holder. To view a copy of this licence, visit http://creativecommons.org/licen ses/by/4.0/.

\section{References}

Anderson, J. R. (1983). Cognitive science series. The architecture of cognition. Hillsdale, NJ: Lawrence Erlbaum Associates, Inc.

Anderson, J. R. (1993). Rules of the mind. Lawrence Erlbaum Associates, Inc.

Anderson, J. R. (2014). Rules of the mind. New York: Psychology Press.

Barsalou, L. W. (2008). Grounded cognition. Annual Review of Psychology, 59, 617-645.

Barsalou, L. W. (2010). Grounded cognition: Past, present, and future. Topics in Cognitive Science, 2(4), 716-724.

Bartolomeo, P., Bourgeois, A., Bourlon, C., \& Migliaccio, R. (2013). Visual and motor mental imagery after brain damage. In S. Lacey \& R. Lawson (Eds.), Multisensory imagery (pp. 249-269). New York, NY: Springer.

Baumeister, R. F. (1984). Choking under pressure: Self-consciousness and paradoxical effects of incentives on skillful performance. Journal of Personality and Social Psychology, 46(3), 610.

Beilock, S. (2010). Choke: What the secrets of the brain reveal about getting it right when you have to. New York: Simon and Schuster.

Beilock, S. L., \& Carr, T. H. (2001). On the fragility of skilled performance: What governs choking under pressure? Journal of experimental psychology: General, 130(4), 701. 
Beilock, S. L., Carr, T. H., MacMahon, C., \& Starkes, J. L. (2002). When paying attention becomes counterproductive: Impact of divided versus skill-focused attention on novice and experienced performance of sensorimotor skills. Journal of Experimental Psychology: Applied, 8(1), 6.

Bengson, J., \& Moffett, M. (2011). Non-propositional intellectualism. In J. Bengson \& M. Moffett (Eds.), Knowing how: Essays on knowledge, mind, and action. Oxford: Oxford University Press.

Bermúdez, J. P. (2017). Do we reflect while performing skillful actions? Automaticity, control, and the perils of distraction. Philosophical Psychology, 30(7), 896-924.

Bernardi, N. F., De Buglio, M., Trimarchi, P. D., Chielli, A., \& Bricolo, E. (2013). Mental practice promotes motor anticipation: Evidence from skilled music performance. Frontiers in Human Neuroscience, 7, 451.

Borst, G., Kievit, R. A., Thompson, W. L., \& Kosslyn, S. M. (2011). Mental rotation is not easily cognitively penetrable. Journal of Cognitive Psychology, 23(1), 60-75.

Bridge, H., Harrold, S., Holmes, E. A., Stokes, M., \& Kennard, C. (2012). Vivid visual mental imagery in the absence of the primary visual cortex. Journal of Neurology, 259(6), 1062-1070.

Brogaard, B., \& Gatzia, D. E. (2017). Unconscious imagination and the mental imagery debate. Frontiers in Psychology, 8, 799.

Brozzo, C. (2017). Motor intentions: How intentions and motor representations come together. Mind \& Language, 32(2), 231-256.

Butterfill, S. A., \& Sinigaglia, C. (2014). Intention and motor representation in purposive action. Philosophy and Phenomenological Research, 88(1), 119-145.

Cath, Y. (2011). Knowing how without knowing that. In M. Bengson \& M. Moffett (Eds.), Knowing how: Essays on knowledge, mind and action (pp. 113-135). Oxford: Oxford University Press.

Chatterjee, A., \& Southwood, M. H. (1995). Cortical blindness and visual imagery. Neurology, 45(12), 2189-2195.

Christensen, W., Sutton, J., \& McIlwain, D. J. (2016). Cognition in skilled action: Meshed control and the varieties of skill experience. Mind \& Language, 31(1), 37-66.

Cohen, M. S., Kosslyn, S. M., Breiter, H. C., DiGirolamo, G. J., Thompson, W. L., Anderson, A. K., et al. (1996). Changes in cortical activity during mental rotation A mapping study using functional MRI. Brain, 119(1), 89-100.

Crammond, D. J. (1997). Motor imagery: Never in your wildest dream. Trends in Neurosciences, 20(2), 54-57.

Currie, G., \& Ravenscroft, I. (1997). Mental simulation and motor imagery. Philosophy of Science, 64(1), $161-180$.

Decety, J. (1996). The neurophysiological basis of motor imagery. Behavioural Brain Research, 77(1-2), 45-52.

Decety, J., \& Boisson, D. (1990). Effect of brain and spinal cord injuries on motor imagery. European Archives of Psychiatry and Clinical Neuroscience, 240(1), 39-43.

Decety, J., \& Jeannerod, M. (1995). Mentally simulated movements in virtual reality: Does Fitt's law hold in motor imagery? Behavioural Brain Research, 72(1-2), 127-134.

Decety, J., Jeannerod, M., \& Prablanc, C. (1989). The timing of mentally represented actions. Behavioural Brain Research, 34(1-2), 35-42.

Decety, J., Kawashima, R., Gulyas, B., \& Roland, P. E. (1992). Preparation for reaching: A PET study of the participating structures in the human brain. Neuroreport: An International Journal for the Rapid Communication of Research. Neuroscience, 3(9), 761-764. https://doi.org/10.1097/00001 756-199209000-00010.

Decety, J., \& Michel, F. (1989). Comparative analysis of actual and mental movement times in two graphic tasks. Brain and Cognition, 11(1), 87-97.

Dechent, P., Merboldt, K. D., \& Frahm, J. (2004). Is the human primary motor cortex involved in motor imagery? Cognitive Brain Research, 19(2), 138-144.

Denis, M., \& Cocude, M. (1989). Scanning visual images generated from verbal descriptions. European Journal of Cognitive Psychology, 1(4), 293-307.

Dominey, P., Decety, J., Broussolle, E., Chazot, G., \& Jeannerod, M. (1995). Motor imagery of a lateralized sequential task is asymmetrically slowed in hemi-Parkinson's patients. Neuropsychologia, 33, $727-741$.

Dretske, F. (1998). Where is the mind when the body performs? Stanford Humanities Review, 6(2). https ://web.stanford.edu/group/SHR/6-2/html/dretske.html.

Dreyfus, H. (2002). Intelligence without representation: Merleau Ponty's critique of representation. Phenomenology and the Cognitive Sciences, 1, 367-383. 
Dreyfus, H., \& Dreyfus, S. (1986). Mind over machine. New York: The Free Press.

Dreyfus, S. E. (2004). The five-stage model of adult skill acquisition. Bulletin of Science, Technology \& Society, 24(3), 177-181.

Driskell, J. E., Copper, C., \& Moran, A. (1994). Does mental practice enhance performance? Journal of Applied Psychology, 79(4), 481.

Duke, R. A., Simmons, A. L., \& Cash, C. D. (2009). It's not how much; it's how: Characteristics of practice behavior and retention of performance skills. Journal of Research in Music Education, 56(4), 310-321.

Feltz, D. L., \& Landers, D. M. (1983). The effects of mental practice on motor skill learning and performance: A metaanalysis. Journal of Sport Psychology, 5(1), 25-57.

Ferretti, G., \& Caiani, S. Z. (2019). Solving the interface problem without translation: The same format thesis. Pacific Philosophical Quarterly, 100(1), 301-333.

Fitts, P. M., \& Posner, M. I. (1967). Human performance. Brooks/Cole.

Fourkas, A. D., Ionta, S., \& Aglioti, S. M. (2006). Influence of imagined posture and imagery modality on corticospinal excitability. Behavioural Brain Research, 168(2), 190-196.

Fridland, E. (2014). They've lost control: Reflections on skill. Synthese, 191(12), 2729-2750.

Fridland, E. (2015). Knowing-how: Problems and considerations. European Journal of Philosophy, 23(3), 703-727.

Fridland, E. (2017a). Skill and motor control: Intelligence all the way down. Philosophical Studies, $174(6), 1539-1560$.

Fridland, E. (2017b). Automatically minded. Synthese, 194(11), 4337-4363.

Fridland, E. (2019a). Longer, smaller, faster, stronger: On skills and intelligence. Philosophical Psychology, 32(5), 759-783.

Fridland, E. (2019b). Intention at the interface. Review of Philosophy and Psychology. https://doi. org/10.1007/s13164-019-00452-x.

Fridland, E. (2021). The nature of skill: Functions and control structures. In E. Fridland \& C. Pavese (Eds.), The Routledge handbook of philosophy of skill and expertise (pp. 245-257). Oxon: Routledge.

Gentili, R., Han, C. E., Schweighofer, N., \& Papaxanthis, C. (2010). Motor learning without doing: Trialby-trial improvement in motor performance during mental training. Journal of Neurophysiology, 104(2), 774-783.

Gentili, R., Papaxanthis, C., \& Pozzo, T. (2006). Improvement and generalization of arm motor performance through motor imagery practice. Neuroscience, 137(3), 761-772.

Georgopoulos, A. P., \& Massey, J. T. (1987). Cognitive spatial-motor processes. Experimental Brain Research, 65(2), 361-370.

Gerardin, E., Sirigu, A., Lehéricy, S., Poline, J. B., Gaymard, B., Marsault, C., et al. (2000). Partially overlapping neural networks for real and imagined hand movements. Cerebral Cortex, 10(11), 1093-1104.

Ghilardi, M. F., Eidelberg, D., Silvestri, G., \& Ghez, C. (2003). The differential effect of PD and normal aging on early explicit sequence learning. Neurology, 60(8), 1313-1319.

Ghilardi, M. F., Feigin, A. S., Battaglia, F., Silvestri, G., Mattis, P., Eidelberg, D., \& Di Rocco, A. (2007). L-Dopa infusion does not improve explicit sequence learning in Parkinson's disease. Parkinsonism \& Related Disorders, 13(3), 146-151.

Ghilardi, M. F., Moisello, C., Silvestri, G., Ghez, C., \& Krakauer, J. W. (2009). Learning of a sequential motor skill comprises explicit and implicit components that consolidate differently. Journal of Neurophysiology, 101(5), 2218-2229.

Guillot, A., Moschberger, K., \& Collet, C. (2013). Coupling movement with imagery as a new perspective for motor imagery practice. Behavioral and Brain Functions, 9(1), 8.

Guillot, A., Nadrowska, E., \& Collet, C. (2009). Using motor imagery to learn tactical movements in basketball. Journal of Sport Behavior, 32(2), 189-206.

Guillot, A., Tolleron, C., \& Collet, C. (2010). Does motor imagery enhance stretching and flexibility? Journal of Sports Sciences, 28(3), 291-298.

Hanakawa, T., Dimyan, M. A., \& Hallett, M. (2008). Motor planning, imagery, and execution in the distributed motor network: A time-course study with functional MRI. Cerebral Cortex, 18(12), 2775-2788.

Hanakawa, T., Immisch, I., Toma, K., Dimyan, M. A., Van Gelderen, P., \& Hallett, M. (2003). Functional properties of brain areas associated with motor execution and imagery. Journal of Neurophysiology, 89(2), 989-1002. 
Hanakawa, T., Parikh, S., Bruno, M. K., \& Hallett, M. (2005). Finger and face representations in the ipsilateralprecentral motor areas in humans. Journal of Neurophysiology, 93(5), 2950-2958.

Hardy, L., \& Callow, N. (1999). Efficacy of external and internal visual imagery perspectives for the enhancement of performance on tasks in which form is important. Journal of Sport and Exercise Psychology, 21(2), 95-112.

Heilman, K. M., Rothi, L. J., \& Valenstein, E. (1982). Two forms of ideomotor apraxia. Neurology, 32(4), $342-342$.

Hodges, N., Huys, R., \& Starkes, J. (2007). Methodological review and evaluation of research in expert performance in sport. In G. Tenenbaum \& R. C. Eklund (Eds.), Handbook of sport psychology (3rd ed., pp. 161-183). Hoboken, NJ: Wiley.

Hommel, B. (2009). Action control according to TEC (theory of event coding). Psychological Research $P R P F, 73(4), 512-526$.

Hommel, B. (2015). The theory of event coding (TEC) as embodied-cognition framework. Frontiers in Psychology, 6, 1318.

Iseki, K., Hanakawa, T., Shinozaki, J., Nankaku, M., \& Fukuyama, H. (2008). Neural mechanisms involved in mental imagery and observation of gait. Neuroimage, 41(3), 1021-1031.

Jeannerod, M. (1994). The representing brain: Neural correlates of motor intention and imagery. Behavioral and Brain Sciences, 17(2), 187-202.

Keller, P. E., Dalla Bella, S., \& Koch, I. (2010). Auditory imagery shapes movement timing and kinematics: Evidence from a musical task. Journal of Experimental Psychology: Human Perception and Performance, 36(2), 508.

Keller, P. E., \& Koch, I. (2006). The planning and execution of short auditory sequences. Psychonomic Bulletin \& Review, 13(4), 711-716.

Keller, P. E., \& Koch, I. (2008). Action planning in sequential skills: Relations to music performance. The Quarterly Journal of Experimental Psychology, 61(2), 275-291.

Kimble, G. A., \& Perlmuter, L. C. (1970). The problem of volition. Psychological Review, 77(5), 361.

Kosslyn, S. M. (1973). Scanning visual images: Some structural implications. Perception \& Psychophysics, 14(1), 90-94.

Kosslyn, S. M. (1999). If neuroimaging is the answer, what is the question? Philosophical Transactions of the Royal Society of London B: Biological Sciences, 354(1387), 1283-1294.

Kosslyn, S. M., Ball, T. M., \& Reiser, B. J. (1978). Visual images preserve metric spatial information: Evidence from studies of image scanning. Journal of Experimental Psychology: Human Perception and Performance, 4(1), 47.

Kosslyn, S. M., Thompson, W. L., \& Ganis, G. (2006). The case for mental imagery. Oxford: Oxford University Press.

Langer, E. J., \& Imber, L. G. (1979). When practice makes imperfect: Debilitating effects of overlearning. Journal of Personality and Social Psychology, 37(11), 2014.

Langheim, F. J., Callicott, J. H., Mattay, V. S., Duyn, J. H., \& Weinberger, D. R. (2002). Cortical systems associated with covert music rehearsal. NeuroImage, 16(4), 901-908.

Lewis, B. P., \& Linder, D. E. (1997). Thinking about choking? Attentional processes and paradoxical performance. Personality and Social Psychology Bulletin, 23(9), 937-944.

Lotze, M., \& Halsband, U. (2006). Motor imagery. Journal of Physiology-Paris, 99(4-6), 386-395.

Lotze, M., Scheler, G., Tan, H. R., Braun, C., \& Birbaumer, N. (2003). The musician's brain: Functional imaging of amateurs and professionals during performance and imagery. Neuroimage, 20(3), 1817-1829.

Madan, C. R., \& Singhal, A. (2012). Motor imagery and higher-level cognition: Four hurdles before research can sprint forward. Cognitive Processing, 13(3), 211-229.

Mahoney, M. J., \& Avener, M. (1977). Psychology of the elite athlete: An exploratory study. Cognitive Therapy and Research, 1(2), 135-141.

Mandelbaum, E. (2016). Attitude, inference, association. Nous, 50, 629-658.

Masters, R. S. (1992). Knowledge, knerves and know-how: The role of explicit versus implicit knowledge in the breakdown of a complex motor skill under pressure. British Journal of Psychology, 83(3), 343-358.

Montero, B. (2016). Thought in action: Expertise and the conscious mind. Oxford: Oxford University Press.

Mylopoulos, M., \& Pacherie, E. (2017). Intentions and motor representations: The interface challenge. Review of Philosophy and Psychology, 8(2), 317-336.

Mylopoulos, M., \& Pacherie, E. (2019). Intentions: The dynamic hierarchical model revisited. Wiley Interdisciplinary Reviews: Cognitive Science, 10(2), e1481. 
Naito, E., Kochiyama, T., Kitada, R., Nakamura, S., Matsumura, M., Yonekura, Y., \& Sadato, N. (2002). Internally simulated movement sensations during motor imagery activate cortical motor areas and the cerebellum. Journal of Neuroscience, 22(9), 3683-3691.

Nanay, B, (forthcoming). Implicit bias as mental imagery. Journal of the American Philosophical Association.

Noë, A. (2005). Against intellectualism. Analysis, 65(4), 278-290.

Ochipa, C., Rapcsak, S. Z., Maher, L. M., Rothi, L. J. G., Bowers, D., \& Heilman, K. M. (1997). Selective deficit of praxis imagery in ideomotor apraxia. Neurology, 49(2), 474-480.

Pacherie, E. (2006). Towards a dynamic theory of intentions. In S. Pockett, W. P. Banks, \& S. Gallagher (Eds.), Does consciousness cause behavior (pp. 145-167). Cambridge: The MIT Press.

Papineau, D. (2013). In the zone. Royal Institute of Philosophy Supplement, 73, 175-196.

Parsons, L. M. (1987). Imagined spatial transformations of one's hands and feet. Cognitive Psychology, 19(2), 178-241.

Pascual-Leone, A., Nguyet, D., Cohen, L. G., Brasil-Neto, J. P., Cammarota, A., \& Hallett, M. (1995). Modulation of muscle responses evoked by transcranial magnetic stimulation during the acquisition of new fine motor skills. Journal of Neurophysiology, 74(3), 1037-1045.

Pavese, C. (2015). Practical senses. Philosopher's Imprint, 15(29), 1-25.

Pavese, C. (2018). Know-how, action, and luck. Synthese. https://doi.org/10.1007/s11229-018-1823-7.

Pavese, C. (2019). The psychological reality of practical representation. Philosophical Psychology, 32(5), 785-822.

Poston, T. (2009). Know how to be gettiered? Philosophy and Phenomenological Research, 79(3), 743-747.

Prinz, J. J. (2004). Gut reactions: A perceptual theory of emotion. Oxford: Oxford University Press.

Prinz, W. (1997). Perception and action planning. European Journal of Cognitive Psychology, 9(2), 129-154.

Reed, C. L. (2002). Chronometric comparisons of imagery to action: Visualizing versus physically performing springboard dives. Memory \& Cognition, 30(8), 1169-1178.

Richardson, A. (1967). Mental practice: a review and discussion part I. Research Quarterly. American Association for Health, Physical Education and Recreation, 38(1), 95-107.

Ryle, G. (1949; reprinted 2009). The concept of mind. London: Routledge.

Schack, T. (2004a). The cognitive architecture of complex movement. International Journal of Sport and Exercise Psychology, 2(4), 403-438.

Schack, T. (2004b). Knowledge and performance in action. Journal of Knowledge Management, 8(4), 38-53.

Schack, T. (2010). Die kognitivearchitekturmenschlicherbewegungen: Innovative zugängefürpsychologie, sportwissenschaft und robotik. Aachen: Meyer \& Meyer Verlag.

Schack, T., Essig, K., Frank, C., \& Koester, D. (2014). Mental representation and motor imagery training. Frontiers in Human Neuroscience, 8, 328.

Schack, T., \& Mechsner, F. (2006). Representation of motor skills in human long-term memory. Neuroscience Letters, 391(3), 77-81.

Schack, T., \& Ritter, H. (2009). The cognitive nature of action-Functional links between cognitive psychology, movement science, and robotics. Progress in Brain Research, 174, 231-250.

Schack, T. (2012). "Measuring mental representations,". In G. Tenenbaum, B. Eklund (Eds.), Handbook of measurement in sport (pp. 203-214). Champaign, IL: Human Kinetics.

Schmidt, R. A. (1975). A schema theory of discrete motor skill learning. Psychological Review, 82(4), 225.

Schmidt, R. A. (2003). Motor schema theory after 27 years: Reflections and implications for a new theory. Research Quarterly for Exercise and Sport, 74(4), 366-375.

Searle, J. (1983). Intentionality. Cambridge: Cambridge University Press.

Shepard, R. N., \& Metzler, J. (1971). Mental rotation of three-dimensional objects. Science, 171(3972), $701-703$

Shepherd, J. (2015). Conscious control over action. Mind \& Language, 30(3), 320-344.

Shepherd, J. (2018). Intelligent action guidance and the use of mixed representational formats. Synthese. https ://doi.org/10.1007/s11229-018-1892-7.

Shepherd, J. (2019). Skilled action and the double life of intention. Philosophy and Phenomenological Research, 98(2), 286-305.

Sirigu, A., Cohen, L., Duhamel, J. R., Pillon, B., Dubois, B., Agid, Y., \& Pierrot-Deseilligny, C. (1995). Congruent unilateral impairments for real and imagined hand movements. NeuroReport, 6(7), 997-1001.

Sirigu, A., Duhamel, J. R., Cohen, L., Pillon, B., Dubois, B., \& Agid, Y. (1996). The mental representation of hand movements after parietal cortex damage. Science, 273(5281), 1564-1568.

Stanley, J., \& Krakauer, J. (2013). Motor skill depends on knowledge of facts. Frontiers of Human Neuroscience. https://doi.org/10.3389/fnhum.2013.0050. 
Stanley, J., \& Willlamson, T. (2001). Knowing how. The Journal of Philosophy, 98(8), 411-444.

Sutton, J., Mcllwain, D., Christensen, W., \& Geeves, A. (2011). Applying intelligence to the reflexes: Embodied skills and habits between Dreyfus and Descartes. Journal of the British Society for Phenomenology, 42(1), 78-103.

Thobois, S., Dominey, P. F., Decety, J., Pollak, P., Gregoire, M. C., Le Bars, D., \& Broussolle, E. (2000). Motor imagery in normal subjects and in asymmetrical Parkinson's disease A PET study. Neurology, 55(7), 996-1002.

Vargas, C. D., Olivier, E., Craighero, L., Fadiga, L., Duhamel, J. R., \& Sirigu, A. (2004). The influence of hand posture on corticospinal excitability during motor imagery: A transcranial magnetic stimulation study. Cerebral Cortex, 14(11), 1200-1206.

Velentzas, K. (2010). Mental representations, routines, and mental training in volleyball (Doctoral dissertation, German Sport University Cologne).

Wu, W. (2015). Experts and deviants: The story of agentive control. Philosophy and Phenomenological Research. https://doi.org/10.1111/phpr.12170.

Yágüez, L., Canavan, A. G., Lange, H. W., \& Hömberg, V. (1999). Motor learning by imagery is differentially affected in Parkinson's and Huntington's diseases. Behavioural Brain Research, 102(1-2), 115-127.

Publisher's Note Springer Nature remains neutral with regard to jurisdictional claims in published maps and institutional affiliations 